\title{
Cytoskeleton alterations in non-alcoholic fatty liver disease
}

\section{João Pessoa ${ }^{\mathrm{a}}$ and José Teixeira ${ }^{\mathrm{a}}$}

${ }^{a}$ CNC - Center for Neuroscience and Cell Biology, CIBB - Center for Innovative Biomedicine and Biotechnology, University of Coimbra, Coimbra, Portugal

Corresponding Author: João Pessoa, CNC - Center for Neuroscience and Cell Biology, University of Coimbra, UC-Biotech, Lot 8A, Biocant Park, Cantanhede 3060-197, Portugal. Phone: (+351) 231249 195, fax: (+351) 231249 179, email address: joao.pessoa@cnc.uc.pt

Declaration of interest: none.

\section{Author Contributions}

J.P.: Conceptualization, data curation, writing - original draft, writing - review \& editing, visualization

J.T.: Writing - review \& editing, visualization

\section{Keywords}

Non-alcoholic fatty liver disease, hepatocytes, hepatic stellate cells, cytoskeleton, a-smooth muscle actin, keratin 18

\begin{abstract}
Abbreviations
NAFLD, non-alcoholic fatty liver disease; MAFLD, metabolic-associated fatty liver disease; NAFL, non-alcoholic fatty liver; NASH, non-alcoholic steatohepatitis; HSCs, hepatic stellate cells; $\alpha-S M A, \alpha$-smooth muscle actin; TGF $\beta$, transforming growth factor $\beta$; MCD, methionine-choline-deficient; LAP1, lamina-associated polypeptide; VLDV, very low density lipoprotein; LC3, light chain 3; CYP4A14, cytochrome P450 omega-hydroxylase 4a14
\end{abstract}

Published article: https://doi.org/10.1016/j.metabol.2021.155115

(C2021. This manuscript version is made available under the CC BY-NC-ND 4.0 license (https://creativecommons.org/licenses/by-nc-nd/4.0/). 


\section{Abstract}

Background: Due to its extremely high prevalence and severity, non-alcoholic fatty liver disease (NALFD) is a serious health and economic concern worldwide. Developing effective methods of diagnosis and therapy demands a deep understanding of its molecular basis. One of the strategies in such an endeavor is the analysis of alterations in the morphology of liver cells. Such alterations, widely reported in NAFLD patients and disease models, are related to the cytoskeleton. Therefore, the fate of the cytoskeleton components is useful to uncover the molecular basis of NAFLD, to further design innovative approaches for its diagnosis and therapy.

Main findings: Several cytoskeleton proteins are up-regulated in liver cells of NAFLD patients. Under pathological conditions, keratin 18 is released from hepatocytes and its detection in the blood emerges as a non-invasive diagnosis tool. a-Smooth muscle actin is up-regulated in hepatic stellate cells and its downregulation has been widely tested as a potential NALFD therapeutic approach. Other cytoskeleton proteins, such as vimentin, are also up-regulated.

Conclusions: NAFLD progression involves alterations in expression levels of proteins that build the liver cytoskeleton or associate with it. These findings provide a timely opportunity of developing novel approaches for NAFLD diagnosis and therapy.

\section{Introduction}

Non-alcoholic fatty liver disease (NALFD), also termed metabolic-associated fatty liver disease (MAFLD) ${ }^{1}$ is an extremely prevalent disease, affecting about $25 \%$ of the global adult population ${ }^{2}$. It is characterized by fat accumulation in more than $5 \%$ of the hepatocytes, the main liver cells. Its initial stage, non-alcoholic fatty liver (NAFL) is characterized by simple steatosis (fat accumulation within cells), without extensive inflammation. It may evolve into non-alcoholic steatohepatitis (NASH), which is characterized by extensive inflammation and fibrosis (permanent accumulation of scar tissue). NAFLD is an important cause of cirrhosis and hepatocellular carcinoma, a frequent indication for liver transplantation and a large health and economic burden². 
There is an obvious and urgent need of designing and testing innovative approaches for NAFLD diagnosis and therapy. Such goals demand a detailed understanding of the molecular and cellular basis of the disease. An important source of insight into such basis is the alteration in the morphology of liver cells ${ }^{3}$, widely reported in NAFLD patients and disease models. Cellular morphology is mostly defined by the cytoskeleton, an extensive protein network within the cell. Therefore, understanding cytoskeleton alterations in NAFLD is also useful to understand disease mechanism and design novel approaches for NAFLD diagnosis and therapy.

In this narrative review, we discuss documented alterations of cytoskeleton proteins in NAFLD context. Some of those alterations provide potential novel tools of diagnosis and therapy, which have been experimentally tested. Finally, we briefly mention some potential future lines of research.

\section{Hepatocyes, Kupffer cells and hepatic stellate cells (HSCs)}

The liver has important functions, including storage and processing of nutrients absorbed through the digestive system and also degradation of toxins, including ethanol ${ }^{4}$. About two-thirds of the liver mass is formed by hepatocytes, whose multiple functions include synthesis of bile and also metabolism of carbohydrates, lipids and proteins ${ }^{5}$. Hepatocytes are highly polarized cells. Their plasma membrane contains distinct sets of proteins and lipids, which are vital for hepatocytes to perform many diverse functions. Hepatocyte polarity requires coordinated functions of supra-molecular structures shaping cell structure, including the cytoskeleton ${ }^{6}$. Abnormal hepatocyte polarization may cause liver diseases, including liver cancer ${ }^{6}$.

These cells are stacked in lines separated by capillaries, the sinusoids (Fig. 1). Hepatocytes stacks form a radial arrangement converging into a central vein. The sinusoids contain macrophage cells called Kupffer cells (Fig. 1), which form about $15 \%$ of the liver cell population. These phagocytic cells eliminate aged erythrocytes and bacteria that may eventually invade the liver ${ }^{7}$. The ruffling of cell membrane and formation of pseudopodia play an important role in the phagocytosis of Kupffer cells and this is believed to be accomplished by the cytoskeleton. In fact, age-related damage of the cytoskeleton system in Kupffer 
cell aging is one of the important mechanisms responsible for a decrease in phagocytosis ${ }^{7}$.

Between hepatocyte stacks and the sinusoidal endothelial cells, the perisinusoidal space (or Space of Disse) is found. This space contains hepatic stellate cells (HSCs) (Fig. 1), or Ito cells ${ }^{8}$. These cells represent about $10 \%$ of all liver cells and store vitamin A inside lipid droplets. HSCs have been primarily characterized as the main effector cells in liver fibrosis, due to their capacity to transdifferentiate into collagen-producing myofibroblasts ${ }^{9}$. HSCs play also a fundamental role in liver immunology, representing a versatile source of many soluble immunological active factors including cytokines. They may act as antigen presenting cells and have autophagic activity. The cytoskeleton of HSCs is also critical for their cellular function. In fact, liver fibrosis in NASH is largely due to excessive extracellular matrix deposition, mediated by cytoskeleton alterations in $\mathrm{HSCs}^{10}$. 


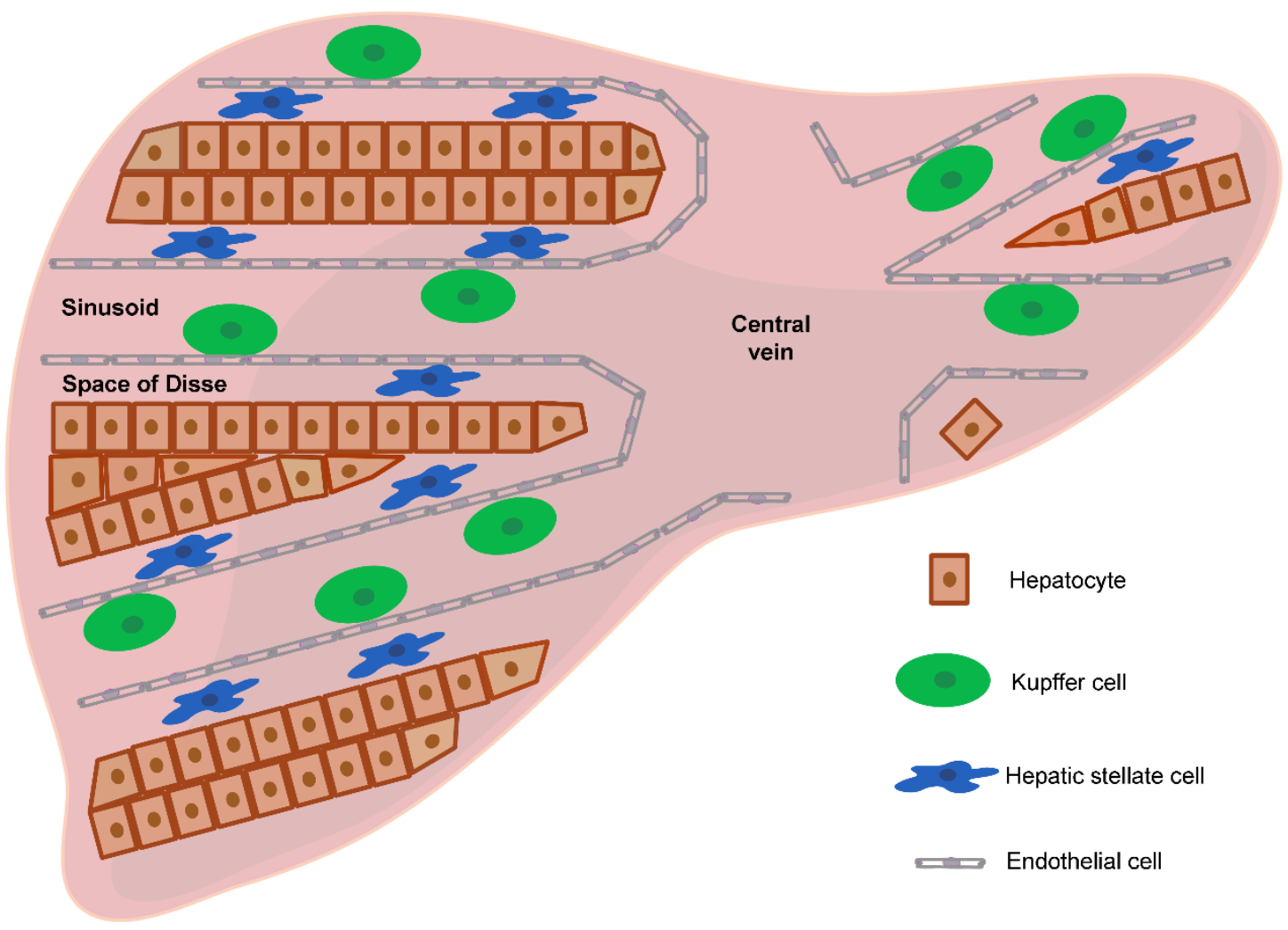

Figure 1: A sketch of liver histology. The sketch represents several sinusoids, defined by epithelial cells (represented in gray), converging into a central vein. Sinusoids contain Kupffer cells (represented in green) attached to epithelial cells. Between sinusoids, hepatocytes (represented in brown) are densely stacked. The space of Disse is comprised between epithelial cells and hepatocyte stacks and contains hepatic stellate cells (represented in blue). The sketch is located within the shape of a human liver. 


\section{Cytoskeleton}

The cytoskeleton is a protein backbone that defines cellular shape and internal structure. It also provides mechanical force and motion for cellular processes, including cell division. The cytoskeleton is divided into microfilaments (or actin filaments), intermediate filaments and microtubules ${ }^{11}$.

The actin cytoskeleton is found in monomeric (globular or $\mathrm{G}$ actin) or polymeric (filamentous or $\mathrm{F}$ actin) forms. Actin filaments are flexible and provide mechanical force to modify movement, shape and contacts. Polymerization, which is mainly regulated by Rho GTPases, is faster in one of the filament ends, generating polarity ${ }^{12}$.

Intermediate filaments have two distinct systems, one located in the cytoplasm, whose composition varies among distinct cell types ${ }^{13}$ and another located in the nucleus, composed of lamin filaments ${ }^{14}$. Intermediate filaments are diverse in protein composition. While hepatocytes contain two types of keratin, keratin 8 and keratin 18, Kupffer cells have vimentin and HSCs have vimentin, desmin, nestin and glial fibrillary acidic protein ${ }^{15}$. Intermediate filaments provide cellular shape and resistance to physical stress ${ }^{13}$.

Microtubules are formed of filaments composed of $\alpha$ - and $\beta$-tubulin heterodimers ${ }^{16}$. Microtubules usually originate at the microtubule organization center, which also contains $y$-tubulin as a polymerization primer. Microtubules function as transport tracks, being also responsible for organelle sub-cellular localization and in mitotic spindle positioning ${ }^{16}$.

Cytoskeleton functioning results of an extensive cross-talk among its components, especially actin filaments and microtubules, which involves crosslinking and mechanical support ${ }^{17}$. Moreover, cytoskeleton proteins can respond to mitochondrial stress, endoplasmic reticulum stress and oxidative stress conditions $^{18}$, which are sub-cellular alterations extensively described in NAFLD. Consequently, proteins from the cytoskeleton of liver cells and their alterations in NAFLD might impact the pathophysiology of the disease and emerge as potential diagnostic hallmarks and/or therapeutic targets. 


\section{Cytoskeleton protein alterations in NAFLD}

\section{1. $\alpha$-Smooth muscle actin and vimentin up-regulation in hepatic stellate cells}

Upon liver injury, hepatic stellate cells $(\mathrm{HSCs})^{8}$ transdifferentiate into myofibroblast-like cells, with a concomitant up-regulation of their a-smooth muscle actin ( $\alpha-S M A){ }^{10}$ and vimentin levels ${ }^{19}$ (Fig. 2). HSCs transdifferentiation is promoted by activation of the focal adhesion kinase by transforming growth factor $\beta$ (TGF $\beta)^{20}$. These transformed cells produce large amounts of collagen and other extracellular matrix components ${ }^{21}$ (Fig. 2). For instance, fibronectin, another extracellular matrix component, was also up-regulated in livers of NAFLD mice $^{22}$. Excessive deposition of extracellular matrix components induces fibrosis, disrupts the normal architecture of the liver and results in hepatic dysfunction ${ }^{23}$. HSCs transdifferentiation into myofibroblast-like cells is the major contributor to liver fibrosis ${ }^{9}$ and $\alpha$-SMA overexpression is a marker of this process.

Studies in human liver biopsies revealed that a-SMA detected in NASH patients was further increased in cirrhosis patients ${ }^{24}$. In pediatric NAFLD patients, liver expression of $\alpha$-SMA increased with fibrosis severity ${ }^{25}$. $\alpha$-SMA levels were also up-regulated in NAFLD mice ${ }^{26}$, rats ${ }^{27}$ and minipigs ${ }^{28}$. These findings show that $\alpha-$ SMA overexpression is a maker of NAFLD progression. 


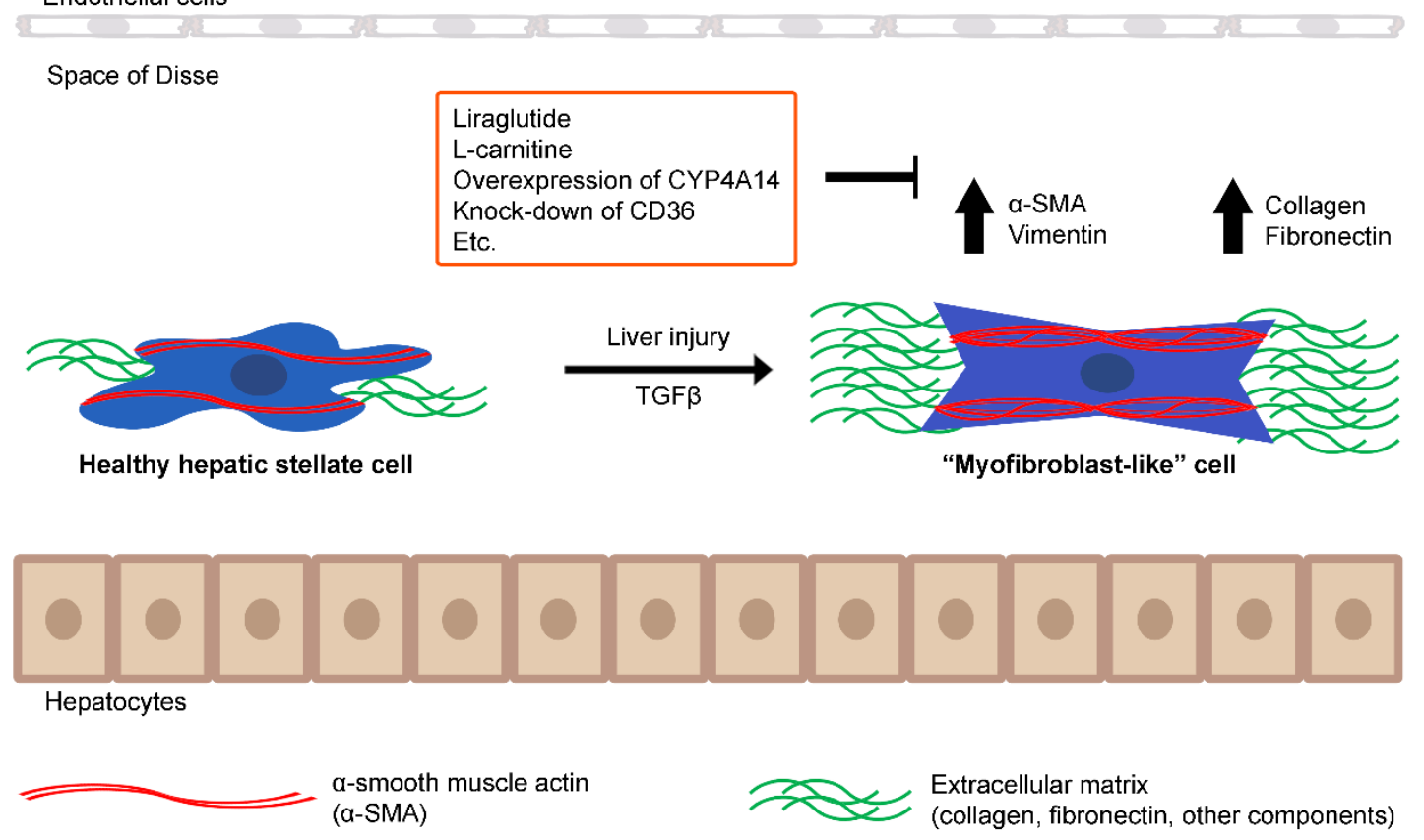

Figure 2: $\alpha$-Smooth muscle actin ( $\alpha$-SMA) up-regulation in injured hepatic stellate cells (HSCs). HSCs (represented in blue) are located in the space of Disse (between hepatocytes and sinusoid epithelial cells). In a healthy liver, HSCs secrete moderate amounts of $\alpha$-SMA (represented in red) and produce moderate amounts of extracellular matrix components (represented in green). Upon liver injury, TGF $\beta$ induces changes in HSC morphology, transdifferenting into myofibroblast-like cells, which overexpress $\alpha$-SMA and vimentin. These changes induce production of large amounts of extracellular matrix components, including collagen and fibronectin. Their excessive deposition results in liver fibrosis and dysfunction. Treatment of animal models with a vast array of compounds, including liraglutide and L-carnitine, as well as through overexpression of cytochrome P450 omega-hydroxylase 4a14 (CYP4A14), has been shown to prevent $\alpha$ SMA up-regulation. Vimentin up-regulation in HSCs and hepatocytes could be prevented through the knockdown of $\mathrm{CD} 36$, also reducing liver damage. 


\subsection{Hepatocyte keratin accumulation into Mallory-Denk bodies}

Fat accumulation in hepatocytes causes cell swelling, vulgarly designated as hepatocyte ballooning, which is a steatohepatitis hallmark. This process is mediated by the two types of hepatocyte keratin (also designated as cytokeratin): keratin 8 and keratin 18. Immunofluorescence staining of these keratins revealed extensive decrease or even loss of intermediate filaments in ballooned hepatocytes ${ }^{29}$. It was proposed that, in NAFLD, intermediate filaments are disassembled, with a simultaneous increase in monomeric keratin synthesis ${ }^{30}$. These alterations cause an excess of keratin $8^{31}$, which favors its misfolding, cross-linking and consequent aggregation ${ }^{32}$. These keratin-rich aggregates, termed Mallory-Denk bodies ${ }^{30}$, are an established NASH marker and a wellknown result of a cytoskeleton alteration in NAFLD.

\subsection{Hepatocyte keratin release into the bloodstream}

The formation of Mallory-Denk bodies is not the only consequence of hepatocyte intermediate filaments disruption in NAFLD. NAFLD involves hepatocyte apoptosis, which generates keratin 18 fragments in the plasma (Fig. 3). Keratin 18 is a marker of hepatocyte apoptosis and an indicator of NAFLD disease progression. Moreover, serum keratin 18 increased in NAFLD patients ${ }^{33}$ and further increased with steatosis, $\mathrm{NASH}$ and fibrosis ${ }^{34}$. Several genetic variants of these two proteins were identified in Chinese NAFLD patients, which were also related to insulin resistance ${ }^{35}$. Moreover, keratin 18 was increased in liver and serum of a mouse model of metabolic syndrome, being considered as a reliable indicator of liver damage ${ }^{36}$.

Keratin 18 is usually detected using antibodies recognizing its M30 or M65 epitopes. While M30 detects keratin 18 fragments released during apoptosis, M65 fails to discriminate these fragments from intact keratin 18 in the intermediate filaments ${ }^{37}$ (Fig. 3). Nevertheless, the keratin 18 M65 epitope has shown to be a better marker to diagnose $\mathrm{NASH}$ than $\mathrm{M} 30^{38}$.

Besides intermediate filament erosion and keratin 18 release, NAFLD may also involve disruption of intermediate filaments attachment to the cell membrane. Treatment with HepG2 cells with palmitate down-regulated desmoplakin ${ }^{39}$, one of the components of a plaque that anchors intermediate filaments to the cell 
membrane. Such down-regulation could lower cell-cell adhesion via desmosomes and disrupt keratin intermediate filaments ${ }^{40}$.

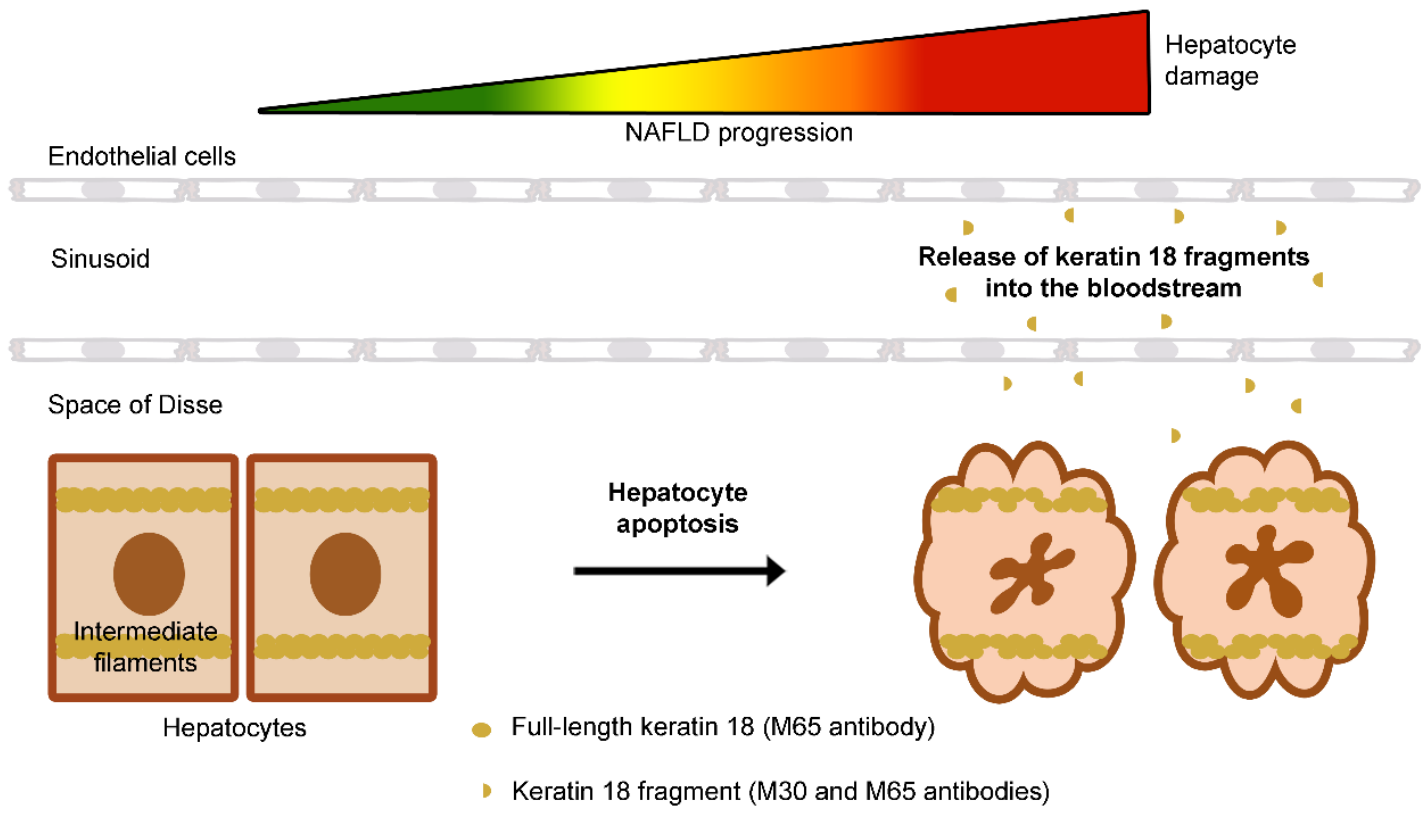

Figure 3: Release of keratin 18 fragments from apoptotic hepatocytes. Upon apoptosis, hepatocyte intermediate filaments (represented in yellow, within hepatocytes represented in brown) release keratin 18 fragments into the sinusoids, which lead to the bloodstream. Released keratin 18 can be detected using specific antibodies. One of these antibodies, named M30, is specific for keratin 18 fragments, while another antibody, M65, detects both full-length and fragmented keratin 18. Serum levels of keratin 18 M30 fragments are correlated with hepatocyte damage and NAFLD progression, which includes severe inflammation, fibrosis, steatosis and ballooning. 


\subsection{Vimentin and desmin up-regulation in hepatocytes and rodent HSCs, respectively}

Vimentin and desmin are additional intermediate filament proteins up-regulated in NAFLD models. In a methionine-choline-deficient (MCD) diet-fed mouse model to induce NASH phenotype, vimentin was up-regulated, cleaved in an apoptosisdependent manner and secreted. Its up-regulation was associated with inflammation, but not directly with lipid accumulation, as vimentin was not significantly up-regulated in mice fed a high-fat diet ${ }^{41}$. A distinct study also detected vimentin up-regulation in hepatocytes of MCD diet-fed mouse model to induce NASH phenotype ${ }^{42}$. Similarly, vimentin was also up-regulated in a NAFLD mouse model (MCD diet-fed-mice) treated with a pro-inflammatory fibrosis inducer ${ }^{22}$. Vimentin up-regulation and cleavage could also be detected in the HepG2 hepatocyte cell line and also in hepatocytes treated with palmitic acid ${ }^{43}$.

Desmin is a marker of rodent HSC activation and was up-regulated in NAFLD rat models ${ }^{44}$. However, it is unclear if this marker is conserved in humans.

\subsection{Lamin A/C and lamin-associated proteins dysfunction in hepatocytes}

The nuclear cytoskeleton is located beneath the inner nuclear membrane. It consists of a filamentous network, the nuclear lamina, composed of intertwined A-type and B-type lamin proteins ${ }^{45}$. The nuclear membrane is also topologically connected to the endoplasmic reticulum, where lipid synthesis occurs ${ }^{46}$. Emerging evidence indicates that lamins and their nuclear membrane-associated proteins have a role in lipid metabolism and could be involved in the development of NAFLD ${ }^{47}$. Some patients with mutations in the LMNA gene, which encodes lamin $\mathrm{A} / \mathrm{C}$, an A-type lamin ${ }^{48}$, developed $\mathrm{NAFLD}{ }^{49,50}$. Two missense heterozygous $L M N A$ mutations associated with nuclear misshaping were found in metabolic syndrome patients ${ }^{51}$, further confirming lamin involvement in NAFLD. Lamin A/C keeps hepatocyte homeostasis and nuclear shape, being found in NAFLD nuclear hepatic inclusions ${ }^{52}$. Hepatocyte-specific deletion of lamin A/C caused steatohepatitis in male mice only. Lamin deficiency also caused nuclear deformity and male-specific increases in sensitivity to diet-induced 
steatohepatitis, fibrosis and hepatocyte growth defects. In these mice, fatty acid metabolism and pro-inflammatory genes were up-regulated ${ }^{53}$. Moreover, sexual dimorphic genes, such as Cyp1a2 and Esr1 (coding for a cytochrome P450 family member and an estrogen receptor, respectively) were de-regulated in mouse hepatocytes ${ }^{54}$. The liver is a sexually dimorphic organ ${ }^{55}$. Although it is unknown why only male mice were prone to steatohepatitis induced by lamin $A / C$ deficiency, these evidences could be a link to the enhanced NAFLD propensity in males ${ }^{56}$.

Lamin-associated proteins have also been implied in NAFLD. The nuclear inner membrane-inserted lamina-associated polypeptide (LAP1) activates torsinA, an ATPase located in the nuclear intermembrane space, to regulate very low density lipoprotein (VLDL) secretion from hepatocytes. Deletion of torsinA or LAP1 in mouse hepatocytes decreased VLDL secretion and caused profound steatosis. Mice carrying each of these deletions developed hepatic steatosis and subsequent steatohepatitis on a regular $\operatorname{diet}^{57}$. These findings indicate that the nuclear cytoskeleton and associated proteins torsinA and LAP1 are required for proper lipid secretion. Their dysfunction could also be involved in NAFLD, through inhibition of lipid secretion.

\section{6. $\alpha$-tubulin up-regulation in mouse hepatocytes}

Microtubules and formed by $\alpha$ - and $\beta$-tubulin heterodimers. Two $\alpha$-tubulin isoforms, tubulin alpha $8^{58}$ and $\alpha$-tubulin $1 \mathrm{~b}$ were up-regulated in tumor tissue of hepatocellular carcinoma patients ${ }^{58,59}$. Although tubulin alpha 8 was also upregulated in a $\mathrm{NASH}$ mouse model ${ }^{60}$, it remains unclear if these two a-tubulin isoforms are also up-regulated in human NAFLD patients.

Fat liver accumulation and oxidative stress in NAFLD can induce lipid peroxidation ${ }^{61}$. Interestingly, two important lipid peroxidation products, the aldehydes 4- hydroxynonenal and 4-oxononenal, were able to inhibit polymerization of purified tubulin ${ }^{62}$ and to rapidly disrupt microtubules in HepG2 cells $^{63}$. Up-regulation of $\alpha$-tubulin isoforms is related to hepatocellular carcinoma and possibly to human NAFLD; however, oxidative stress may have a counterbalancing effect. 


\subsection{Light chain 3 (LC3) isoform distribution alterations}

Light chain 3 (LC3), a common subunit of two microtubule-binding proteins, is found in two isoforms. LC3-I is cytosolic, whereas LC3-II locates in autophagosome membranes, being its cellular level correlated with the extent of autophagosome formation and accumulation ${ }^{64}$. LC3 participates in autophagy, eliminating old or damaged mitochondria and endoplasmic reticulum ${ }^{65}$. The LC3II isoform is likely to attach autophagosomes to microtubules ${ }^{64}$.

A NAFLD mouse model has shown impaired autophagy and enhanced conversion of LC3-I to LC3-II66, which was also observed in the livers of rats fed with a high fat and high cholesterol diet ${ }^{67}$. The excess of LC3-II suggests autophagosome accumulation in hepatic cells, which could in part explain the autophagy deficiency observed in NAFLD ${ }^{68}$. Therefore, the cytoskeleton could also be involved in such a deficiency, through LC3-II attachment to microtubules. In ovariectomized rats, there was also increased hepatic fat accumulation and concomitant decrease in LC3-169, which suggests impairment of lipid droplets autophagy (lipophagy). This finding also suggests a possible explanation for increased female propensity to NAFLD after menopause ${ }^{70}$, when the ovaries decrease estrogen production.

\section{Cytoskeleton protein in NAFLD diagnosis}

Release of keratin from hepatocyte intermediate filaments is one of the clinically most useful cytoskeleton alterations in NAFLD. Quantification of keratin 18 in patient serum has been extensively tested, frequently in combination with more established NAFLD markers (Table 1). In NAFLD diagnosis, it emerges as a promising alternative to liver biopsy.

In conjunction with other markers, keratin 18 was proposed as a biomarker for fibrotic NASH diagnosis ${ }^{71-73}$, whose quantification provides the most used biomarker of steatohepatitis, despite its low accuracy ${ }^{74}$. Their quantification has shown to have a good predictive ability for $\mathrm{NASH}$ diagnosis ${ }^{75}$, and associated positively with serum alanine aminotransferase ${ }^{76}$, another NASH marker. Keratin 
18 was proposed as a non-invasive biomarker of early apoptosis, useful to diagnose NASH and differentiate it from simple steatosis ${ }^{77}$.

Quantification of keratin 18 fragments was able to predict prognosis of NAFLD patients ${ }^{78}$. Serum keratin 18 fragment levels decreased in obese, liver fibrosis patients, upon diet-induced weight loss ${ }^{79}$ and upon physical exercise therapy ${ }^{80}$. Such a decrease was correlated with alleviation in steatosis and fibrosis ${ }^{79}$. Keratin 18 fragment levels also decreased after bariatric surgery ${ }^{81}$ and such decrease was positively correlated with improvement in liver histology in adults or children with NAFLD ${ }^{82}$ (Table 1). In fact, using a NAFLD rat model, serum levels of keratin 18 fragments were increased in more severe inflammation, fibrosis, steatosis and balooning NAFLD disease stages ${ }^{83}$.

Additionally, quantification of secreted vimentin was also proposed as a potential diagnosis method for $\mathrm{NASH}^{41}$. Notwithstanding, more consistent data should be experimentally acquired in the future.

In summary, cytoskeleton proteins, especially keratin 18 fragments, are an important biomarker of NAFLD disease progression and their quantification in the blood emerges as a non-invasive diagnosis tool. 
Table 1: Studies on NAFLD diagnosis based on quantification of keratin 18 fragments in patient serum

\begin{tabular}{|c|c|c|c|c|c|c|}
\hline $\begin{array}{l}\text { Antibody } \\
\text { type }\end{array}$ & $\begin{array}{l}\text { Participants } \\
\text { / model } \\
\text { systems }\end{array}$ & Diet & $\begin{array}{l}\text { Disease } \\
\text { stage }\end{array}$ & Remarks & Year & Reference \\
\hline M30 & $\begin{array}{c}\text { Adult } \\
\text { patients }\end{array}$ & $\mathrm{N} / \mathrm{A}$ & $\begin{array}{l}\text { Active and } \\
\text { fibrotic NASH }\end{array}$ & $\begin{array}{c}\text { Used in conjunction with } \\
\text { quantification of aspartate } \\
\text { aminotransferase and assessment } \\
\text { of insulin resistance }\end{array}$ & 2019 & 71 \\
\hline M30 & Rat & High-fat & $\mathrm{NASH}$ & $\begin{array}{c}\text { Used in conjunction with } \\
\text { quantification of interferon- } \lambda 3 \text { / IL- } \\
28 \mathrm{~B}\end{array}$ & 2020 & 73 \\
\hline $\begin{array}{c}\text { (Not } \\
\text { specified) }\end{array}$ & $\begin{array}{c}\text { Adult } \\
\text { patients }\end{array}$ & $\mathrm{N} / \mathrm{A}$ & $\begin{array}{l}\text { NAFL and } \\
\text { NASH }\end{array}$ & $\begin{array}{l}\text { Used in conjunction with } \\
\text { assessments of fibrosis index and } \\
\text { insulin resistance }\end{array}$ & 2019 & 72 \\
\hline M30 & $\begin{array}{c}\text { Adult } \\
\text { patients }\end{array}$ & $\mathrm{N} / \mathrm{A}$ & (Not specified) & $\begin{array}{c}\text { Used in conjunction with } \\
\text { quantifications of alanine } \\
\text { aminotransferase and aspartate }\end{array}$ & 2020 & 76 \\
\hline $\begin{array}{l}\text { M30 and } \\
\text { M65 }\end{array}$ & $\begin{array}{c}\text { Adult } \\
\text { patients }\end{array}$ & $\mathrm{N} / \mathrm{A}$ & $\begin{array}{l}\text { NAFL and } \\
\text { suspected } \\
\text { NASH }\end{array}$ & $\begin{array}{c}\text { Used in conjunction with } \\
\text { quantification of fibroblast growth } \\
\text { factor } 21\end{array}$ & 2017 & 78 \\
\hline M30 & $\begin{array}{c}\text { Adult } \\
\text { patients }\end{array}$ & $N / A$ & Fibrosis & $\begin{array}{l}\text { Used to monitor the effect of diet- } \\
\text { induced weight loss }\end{array}$ & 2019 & 79 \\
\hline M65 & $\begin{array}{c}\text { Adult } \\
\text { patients }\end{array}$ & $\mathrm{N} / \mathrm{A}$ & (Not specified) & $\begin{array}{c}\text { Used in conjunction with } \\
\text { quantification of fibroblast growth } \\
\text { factor } 21 \text { and to monitor the effect of } \\
\text { physical exercise }\end{array}$ & 2020 & 80 \\
\hline M30 & $\begin{array}{c}\text { Adult } \\
\text { patients }\end{array}$ & $\mathrm{N} / \mathrm{A}$ & (Not specified) & $\begin{array}{l}\text { Used to monitor the effect of } \\
\text { bariatric surgery; inconsistent results }\end{array}$ & 2021 & 81 \\
\hline M30 & $\begin{array}{l}\text { Adult and } \\
\text { pediatric } \\
\text { patients }\end{array}$ & $\mathrm{N} / \mathrm{A}$ & $\begin{array}{l}\text { NAFL and } \\
\text { NASH }\end{array}$ & $\begin{array}{l}\text { Used to monitor changes in liver } \\
\text { histology }\end{array}$ & 2014 & 82 \\
\hline M30 & Rat & $\begin{array}{l}\text { High- } \\
\text { sucrose, } \\
\text { high-fat }\end{array}$ & $\begin{array}{l}\text { NAFL and } \\
\text { NASH }\end{array}$ & $\begin{array}{l}\text { Used to monitor changes in liver } \\
\text { histology }\end{array}$ & 2018 & 83 \\
\hline
\end{tabular}




\section{Therapeutic perspectives}

\subsection{Down-regulation of $\alpha-S M A$ and vimentin}

The cytoskeleton has been successfully tested as a potential therapeutic target in NAFLD. Many drugs, in several animal and cellular models, which were effective in NAFLD alleviation, were found to down-regulate a-SMA in HSCs (Table 2). Feeding of NASH minipigs with a chinese herbal medicine significantly inhibited a-SMA expression, as well as hepatocyte fibrosis ${ }^{28}$. In NASH mouse models, several compound treatments were effective in down-regulating a-SMA and inhibited HSC transformation, alleviating NASH features, including steatosis and fibrosis. Those compounds include resmetirom, a liver-directed, selective thyroid hormone receptor $\beta$ agonist ${ }^{84}$, the glucagon-like peptide 1 analog liraglutide ${ }^{85}$, eugenol ${ }^{86}$, diosmin ${ }^{87}$, amlexanox, an inhibitor of nuclear factor $\mathrm{kB}$ kinase epsilon and TANK-binding kinase ${ }^{188}$, L-carnitine, a fatty acid $\beta$-oxidation cofactor $^{89}$, namodenoson, an anti-inflammatory adenosine derivative ${ }^{90}$, gypenoside LXXV, a ginseng-extracted compound ${ }^{91}$, fermented black radish ${ }^{92}$, zoledronic acid ${ }^{93}$, a sirtuin inhibitor ${ }^{94}$ and many more.

a-SMA expression in HSCs could also be lowered through overexpression of cytochrome P450 omega-hydroxylase 4a14 (CYP4A14) ${ }^{95}$ or through knock-out of renalase (an oxidative stress suppressor) in NASH mice ${ }^{96}$. Inhibition of focal adhesion kinase reduced $\alpha$-SMA and collagen overexpression in an animal model, in the presence of TGF $\beta^{20}$ (Table 2). Although these studies pertain to HSCs, $\alpha$-SMA expression was also lowered in hepatocytes through knockdown of CD36, a glycoprotein that promotes lipid transport ${ }^{43}$. Thus, the HSC cytoskeleton protein $\alpha$-SMA has been widely shown as a promising drug target in NAFLD, including in advanced disease stages.

Although less extensively tested, down-regulation of vimentin, another cytoskeleton protein, has also shown a promising outcome in NAFLD models. Vimentin was up-regulated in mouse $\mathrm{HSCs}^{19}$ and in human hepatocytes treated with palmitic acid ${ }^{43}$. Knockdown of CD36 reduced both lipid and vimentin levels in hepatocytes ${ }^{43}$. In plasma samples from patients and rat models, vimentin upregulation was also correlated to increased fibrosis. Interestingly, knockdown of vimentin in rat HSCs inhibited the transdifferentiation into myofibroblasts ${ }^{97}$. These 
studies indicate that down-regulation of vimentin could also be useful in NAFLD

treatment, in addition to the many approaches shown to down-regulate $\alpha$-SMA (Fig. 2). 
Table 2: Studies on NAFLD therapeutic approaches based on $\alpha$-smooth muscle actin down-regulation in hepatic stellate cells

\begin{tabular}{|c|c|c|c|c|c|c|}
\hline $\begin{array}{l}\text { Drug / protein level } \\
\text { alteration }\end{array}$ & $\begin{array}{c}\text { Model } \\
\text { system(s) }\end{array}$ & $\begin{array}{c}\text { Diet / } \\
\text { treatment }\end{array}$ & $\begin{array}{l}\text { Disease } \\
\text { stage }\end{array}$ & Remarks & Year & Reference \\
\hline $\begin{array}{l}\text { Fufang Zhenzhu Tiaozhi } \\
\text { formula (a preparation of } \\
\text { Chinese herbal } \\
\text { medicine) }\end{array}$ & $\begin{array}{l}\text { Minipig, } \\
\text { HepG2 } \\
\text { cell line }\end{array}$ & $\begin{array}{l}\text { High-fat / } \\
\text { oleic acid, } \\
\text { palmitic acid }\end{array}$ & $\overline{\mathrm{NASH}}$ & $\begin{array}{l}\text { Effect mediated by the } \\
\text { adenosine } \\
\text { monophosphate-activated } \\
\text { protein kinase (AMPK) } \\
\text { signaling pathway }\end{array}$ & 2021 & 28 \\
\hline $\begin{array}{c}\text { Resmetirom, a thyroid } \\
\text { hormone receptor } \\
\beta \text { agonist }\end{array}$ & Mouse & $\begin{array}{l}\text { High-fat, } \\
\text { high- } \\
\text { fructose, } \\
\text { high- } \\
\text { cholesterol }\end{array}$ & $\begin{array}{l}\text { NASH and } \\
\text { fibrosis }\end{array}$ & $\begin{array}{c}\text { Treatment reduced liver } \\
\text { weight without affecting } \\
\text { body weight }\end{array}$ & 2021 & 84 \\
\hline $\begin{array}{l}\text { Liraglutide, a glucagon- } \\
\text { like peptide } 1 \text { analog }\end{array}$ & Mouse & $\begin{array}{l}\text { High-fat, } \\
\text { high- } \\
\text { fructose, } \\
\text { high- } \\
\text { cholesterol }\end{array}$ & $\mathrm{NASH}$ & $\begin{array}{l}\text { Treatments decreased } \\
\text { inflammation and fibrosis; } \\
\text { elafibranor was also } \\
\text { tested, affecting hepatic } \\
\text { lipid composition }\end{array}$ & 2021 & 85 \\
\hline $\begin{array}{l}\text { Eugenol, a compound } \\
\text { extracted from essential } \\
\text { oils }\end{array}$ & Rat & High-fat & Fibrosis & $\begin{array}{l}\text { Treatment affected insulin } \\
\text { resistance }\end{array}$ & 2021 & 86 \\
\hline $\begin{array}{l}\text { Diosmin, an anti-clotting } \\
\text { compound }\end{array}$ & Rat & High-fat & $\mathrm{NASH}$ & $\begin{array}{l}\text { Treatment has shown } \\
\text { effects in insulin } \\
\text { resistance, inflammation } \\
\text { and fibrosis }\end{array}$ & 2020 & 87 \\
\hline $\begin{array}{l}\text { Amlexanox, an anti- } \\
\text { inflammatory compound }\end{array}$ & Mouse & $\begin{array}{l}\text { High-fat } \\
\text { and/or } \\
\text { lipopolysacc } \\
\text { haride }\end{array}$ & $\begin{array}{c}\text { (Not } \\
\text { specified) }\end{array}$ & $\begin{array}{l}\text { Treatment has shown } \\
\text { effects in insulin resistance } \\
\text { and inflammation }\end{array}$ & 2019 & 88 \\
\hline $\begin{array}{l}\text { L-carnitine, a fatty acid } \\
\beta \text {-oxidation cofactor }\end{array}$ & Mouse & $\begin{array}{l}\text { Methionine- } \\
\text { choline- } \\
\text { deficient }\end{array}$ & NAFL & $\begin{array}{l}\text { Treatment has shown } \\
\text { effects on inflammation, } \\
\text { reactive oxygen species } \\
\text { production and fibrosis }\end{array}$ & 2020 & 89 \\
\hline $\begin{array}{l}\text { Namodenoson, a } \\
\text { compound with anti- } \\
\text { hepatocellular } \\
\text { carcinoma effect }\end{array}$ & Mouse & $\begin{array}{l}\text { High-fat and } \\
\text { streptozotoci } \\
\mathrm{n}\end{array}$ & $\mathrm{NASH}$ & $\begin{array}{l}\text { Treatment inhibited liver } \\
\text { ischemia / reperfusion } \\
\text { injury }\end{array}$ & 2019 & 90 \\
\hline $\begin{array}{l}\text { Gypenoside LXXV, a } \\
\text { ginseng-extracted } \\
\text { compound }\end{array}$ & $\begin{array}{l}\text { Mouse, } \\
\text { HepG2 } \\
\text { and LX2 } \\
\text { cell lines }\end{array}$ & $\begin{array}{l}\text { Methionine- } \\
\text { choline- } \\
\text { deficient / } \\
\text { palmitic acid }\end{array}$ & $\mathrm{NASH}$ & $\begin{array}{c}\text { Treatment prevented liver } \\
\text { injury and activation of } \\
\text { hepatic macrophages }\end{array}$ & 2020 & 91 \\
\hline
\end{tabular}


Table 2: Studies on NAFLD therapeutic approaches based on $\alpha$-smooth muscle actin down-regulation in hepatic stellate cells (cont.)

\begin{tabular}{|c|c|c|c|c|c|c|}
\hline $\begin{array}{l}\text { Drug / protein level } \\
\text { alteration }\end{array}$ & $\begin{array}{c}\text { Model } \\
\text { system(s) }\end{array}$ & $\begin{array}{l}\text { Diet / } \\
\text { treatment }\end{array}$ & $\begin{array}{l}\text { Disease } \\
\text { stage }\end{array}$ & Remarks & Year & Reference \\
\hline Fermented black radish & Mouse & $\begin{array}{l}\text { Methionine- } \\
\text { choline- } \\
\text { deficient }\end{array}$ & Fibrosis & $\begin{array}{l}\text { Treatment suppressed } \\
\text { activation of Kupffer cells } \\
\text { and other liver } \\
\text { macrophages }\end{array}$ & 2019 & 92 \\
\hline $\begin{array}{c}\text { Zoledronic acid, a } \\
\text { compound that lowers } \\
\text { excessive calcium levels } \\
\text { in the blood }\end{array}$ & Rat & High-fat & $\mathrm{NASH}$ & $\begin{array}{l}\text { Treatment resulted in } \\
\text { decreased portal vein } \\
\text { hypertension }\end{array}$ & 2019 & 93 \\
\hline $\begin{array}{l}\text { EX-527, an inhibitor of } \\
\text { sirtuin } 1 \text { (a metabolic } \\
\text { regulator) }\end{array}$ & Rat & High-fat & Fibrosis & $\begin{array}{c}\text { Treatment up-regulated } \\
\text { sirtuins 2, } 3 \text { and } 4\end{array}$ & 2020 & 94 \\
\hline $\begin{array}{l}\text { Hepatic overexpression } \\
\text { of cytochrome P450 } \\
\text { omega-hydroxylase } \\
\text { 4a14 (CYP4A14) }\end{array}$ & Mouse & $\begin{array}{l}\text { Bile duct } \\
\text { ligation }\end{array}$ & Fibrosis & $\begin{array}{l}\text { Knock-out of the same } \\
\text { protein in mice aggravated } \\
\text { transdifferentiation of } \\
\text { HSCs into myofibroblasts }\end{array}$ & 2021 & 95 \\
\hline $\begin{array}{l}\text { Knock-out of renalase, } \\
\text { an enzyme down- } \\
\text { regulated in kidney } \\
\text { disease }\end{array}$ & Mouse & $\begin{array}{l}\text { choline-defi } \\
\text { cient, } \\
\text { high-fat, } \\
\text { supplement } \\
\text { ed with } \\
0.1 \% \text { methio } \\
\text { nine }\end{array}$ & $\mathrm{NASH}$ & $\begin{array}{l}\text { Treatment showed a } \\
\text { modest effect in NASH } \\
\text { suppression }\end{array}$ & 2021 & 96 \\
\hline $\begin{array}{l}\text { Inhibition of focal } \\
\text { adhesion kinase }\end{array}$ & $\begin{array}{l}\text { Mouse; } \\
\text { mouse } \\
\text { HSCs }\end{array}$ & $\begin{array}{c}\text { Carbon } \\
\text { tetrachloride }\end{array}$ & Fibrosis & $\begin{array}{c}\text { Treatment inhibited TGF } \beta \\
\text { effect in HSC } \\
\text { transdifferentiation }\end{array}$ & 2017 & 20 \\
\hline
\end{tabular}

Additional studies could not be listed here, due to reference number limitations. 


\subsection{Inhibition of keratin release and modulation of LC3-II}

Inhibition of keratin release from hepatocyte intermediate filaments could be another therapeutic possibility. Treatment of a NASH mouse model with fenofibrate inhibited disruption of intermediate filaments and consequent formation of Mallory-Denk bodies, further reducing oxidative stress and inflammation ${ }^{98}$ and improving the phenotype.

Restoring cellular levels of LC3-II, the LC3 isoform attaching autophagosomes to microtubules, has shown to alleviate steatosis by reestablishing lipid droplets autophagy. Treatment of high-fat diet mice and hepatocytes exposed to palmitic acid with liraglutide, a glucagon-like peptide 1 analog, restored the autophagic fluxes in these systems, decreased fat accumulation and improving the NAFLD phenotype ${ }^{99,100}$. These studies show that this microtubule-associated protein could be an interesting element for autophagy restoration in NAFLD.

\section{Concluding Remarks}

In the present review, we have analyzed available information concerning the roles of cytoskeleton proteins in NAFLD. In the literature, alterations in cytoskeleton proteins have been associated to the development of liver steatosis, fibrosis, cirrhosis, and hepatocellular carcinoma. Several of the major scaffold proteins of the cytoskeleton are up-regulated in NAFLD and their down-regulation could be a therapeutic approach. Concerning cytoskeleton interventions as prospective NAFLD therapies, down-regulation of $\alpha$-SMA is clearly the most extensively tested approach, which inhibits excessive growth of the extracellular matrix, an important cause of fibrosis. a-SMA down-regulation as a promising NAFLD therapeutic approach is impressive. Consequently, down-regulation of vimentin, inhibition of keratin release and modulation of LC3-II are starting to be tested as other potential therapeutic approaches. Notwithstanding, the roles of cytoskeleton motor proteins, including kinesins, dyneins and myosin, seem to be unexplored in NAFLD. Moreover, cytoskeleton proteins are highly regulated, frequently through post-translational modifications ${ }^{101}$, a topic that seem also to be unexplored in NAFLD. It becomes now imperative to explore the physiological relevance of cytoskeleton proteins in liver pathophysiology and metabolic diseases, as well as their roles as potential therapeutic targets in NAFLD. 
These findings show that the cytoskeleton has a promising therapeutic potential in NAFLD, which is a still poorly explored system, demanding to be further investigated in the NAFLD context.

\section{Acknowledgements}

This work was financed by the European Regional Development Fund (ERDF), through the COMPETE 2020 - Operational Programme for Competitiveness and Internationalisation and Portuguese national funds via FCT - Fundação para a Ciência e a Tecnologia, under projects POCI-01-0145-FEDER-028147 (VISCERAL), UIDB/04539/2020 and UIDP/04539/2020. J.P. (POCI-01-0145FEDER-028147 (VISCERAL)) and J.T. (2020.01560.CEECIND) acknowledge FCT for the research contracts. The authors have no conflicts of interest to disclose.

\section{References}

Eslam, M., Sanyal, A. J. \& George, J. MAFLD: A Consensus-Driven Proposed Nomenclature for Metabolic Associated Fatty Liver Disease. Gastroenterology 158, 1999-2014 e1991, doi:10.1053/j.gastro.2019.11.312 (2020). Targher, G., Tilg, H. \& Byrne, C. D. Non-alcoholic fatty liver disease: a multisystem disease requiring a multidisciplinary and holistic approach. The lancet. Gastroenterology \& hepatology 6 , 578-588, doi:10.1016/s2468-1253(21)00020-0 (2021). Cataldo, I. et al. Pathology of non-alcoholic fatty liver disease. Pathologica 113, 194-202, doi:10.32074/1591-951x-242 (2021). Trefts, E., Gannon, M. \& Wasserman, D. H. The liver. Current biology : CB 27, R1147-R1151, doi:10.1016/j.cub.2017.09.019 (2017).

5 Zhou, Z., Xu, M. J. \& Gao, B. Hepatocytes: a key cell type for innate immunity. Cellular \& molecular immunology 13, 301-315, doi:10.1038/cmi.2015.97 (2016). Gissen, P. \& Arias, I. M. Structural and functional hepatocyte polarity and liver disease. Journal of hepatology 63, 1023-1037, doi:10.1016/j.jhep.2015.06.015 (2015). Nguyen-Lefebvre, A. T. \& Horuzsko, A. Kupffer Cell Metabolism and Function. Journal of enzymology and metabolism 1 (2015). Kordes, C., Bock, H. H., Reichert, D., May, P. \& Häussinger, D. Hepatic stellate cells: current state and open questions. Biological chemistry 402, 1021-1032, doi:10.1515/hsz-2021-0180 (2021). Yan, Y., Zeng, J., Xing, L. \& Li, C. Extra- and Intra-Cellular Mechanisms of Hepatic Stellate Cell Activation. Biomedicines 9, doi:10.3390/biomedicines9081014 (2021). Cui, X. et al. F-actin cytoskeleton reorganization is associated with hepatic stellate cell activation. Molecular medicine reports 9, 1641-1647, doi:10.3892/mmr.2014.2036 (2014). Hohmann, T. \& Dehghani, F. The Cytoskeleton-A Complex Interacting Meshwork. Cells 8, doi:10.3390/cells8040362 (2019). 
Filić, V. et al. Regulation of the Actin Cytoskeleton via Rho GTPase Signalling in Dictyostelium and Mammalian Cells: A Parallel Slalom. Cells 10, doi:10.3390/cells10071592 (2021).

Etienne-Manneville, S. Cytoplasmic Intermediate Filaments in Cell Biology. Annual review of cell and developmental biology 34, 1-28, doi:10.1146/annurev-cellbio-100617-062534 (2018).

Gruenbaum, Y. \& Foisner, R. Lamins: nuclear intermediate filament proteins with fundamental functions in nuclear mechanics and genome regulation. Annual review of biochemistry 84, 131164, doi:10.1146/annurev-biochem-060614-034115 (2015).

Strnad, P., Stumptner, C., Zatloukal, K. \& Denk, H. Intermediate filament cytoskeleton of the liver in health and disease. Histochemistry and cell biology 129, 735-749, doi:10.1007/s00418-0080431-x (2008).

Kristensson, M. A. The Game of Tubulins. Cells 10, doi:10.3390/cells10040745 (2021).

Dogterom, M. \& Koenderink, G. H. Actin-microtubule crosstalk in cell biology. Nature reviews. Molecular cell biology 20, 38-54, doi:10.1038/s41580-018-0067-1 (2019).

Ong, M. S. et al. Cytoskeletal Proteins in Cancer and Intracellular Stress: A Therapeutic Perspective. Cancers 12, doi:10.3390/cancers12010238 (2020).

Geerts, A. et al. Formation of normal desmin intermediate filaments in mouse hepatic stellate cells requires vimentin. Hepatology (Baltimore, Md.) 33, 177-188, doi:10.1053/jhep.2001.21045 (2001). Zhao, X. K. et al. Focal Adhesion Kinase Regulates Hepatic Stellate Cell Activation and Liver Fibrosis. Scientific reports 7, 4032, doi:10.1038/s41598-017-04317-0 (2017).

Hernandez-Gea, V. \& Friedman, S. L. Pathogenesis of liver fibrosis. Annual review of pathology 6 , 425-456, doi:10.1146/annurev-pathol-011110-130246 (2011).

Heo, Y. J. et al. Visfatin exacerbates hepatic inflammation and fibrosis in a methionine-cholinedeficient diet mouse model. Journal of gastroenterology and hepatology 36, 2592-2600, doi:10.1111/jgh.15465 (2021).

Ortiz, C. et al. Extracellular Matrix Remodeling in Chronic Liver Disease. Current tissue microenvironment reports, 1-12, doi:10.1007/s43152-021-00030-3 (2021).

Sanyal, A. J. et al. The Natural History of Advanced Fibrosis Due to Nonalcoholic Steatohepatitis: Data From the Simtuzumab Trials. Hepatology (Baltimore, Md.) 70, 1913-1927, doi:10.1002/hep.30664 (2019).

de Oliveira, F. L. et al. The Number of Liver Galectin-3 Positive Cells Is Dually Correlated with NAFLD Severity in Children. International journal of molecular sciences $\mathbf{2 0}$, doi:10.3390/ijms20143460 (2019).

Takayama, S. et al. Partially hydrolyzed guar gum attenuates non-alcoholic fatty liver disease in mice through the gut-liver axis. World journal of gastroenterology 27, 2160-2176, doi:10.3748/wjg.v27.118.2160 (2021).

El-Derany, M. O. \& El-Demerdash, E. Pyrvinium pamoate attenuates non-alcoholic steatohepatitis: Insight on hedgehog/Gli and Wnt/ $/$-catenin signaling crosstalk. Biochemical pharmacology 177, 113942, doi:10.1016/j.bcp.2020.113942 (2020).

Wang, H. et al. FTZ attenuates liver steatosis and fibrosis in the minipigs with type 2 diabetes by regulating the AMPK signaling pathway. Biomedicine \& pharmacotherapy $=$ Biomedecine \& pharmacotherapie 138, 111532, doi:10.1016/j.biopha.2021.111532 (2021).

Lackner, C. et al. Ballooned hepatocytes in steatohepatitis: the value of keratin immunohistochemistry for diagnosis. Journal of hepatology 48, 821-828, doi:10.1016/j.jhep.2008.01.026 (2008). 
Stumptner, C., Fuchsbichler, A., Lehner, M., Zatloukal, K. \& Denk, H. Sequence of events in the assembly of Mallory body components in mouse liver: clues to the pathogenesis and significance of Mallory body formation. Journal of hepatology 34, 665-675, doi:10.1016/s0168-8278(00)000994 (2001).

Nakamichi, I. et al. Keratin 8 overexpression promotes mouse Mallory body formation. The Journal of cell biology 171, 931-937, doi:10.1083/jcb.200507093 (2005).

Kucukoglu, O. et al. High-fat diet triggers Mallory-Denk body formation through misfolding and crosslinking of excess keratin 8. Hepatology (Baltimore, Md.) 60, 169-178, doi:10.1002/hep.27068 (2014).

Chang, Y. H. et al. Elevated serum cytokeratin-18 concentration in patients with type 2 diabetes mellitus and non-alcoholic fatty liver disease. Annals of clinical biochemistry 56, 141-147, doi:10.1177/0004563218796259 (2019).

Darweesh, S. K. et al. Serum cytokeratin-18 and its relation to liver fibrosis and steatosis diagnosed by FibroScan and controlled attenuation parameter in nonalcoholic fatty liver disease and hepatitis C virus patients. European journal of gastroenterology \& hepatology 31, 633-641, doi:10.1097/meg.0000000000001385 (2019).

$\mathrm{Li}, \mathrm{R}$. et al. Association of keratin 8/18 variants with non-alcoholic fatty liver disease and insulin resistance in Chinese patients: A case-control study. World journal of gastroenterology 23, 40474053, doi:10.3748/wjg.v23.i22.4047 (2017).

Bratoeva, K. et al. Association Between Serum CK-18 Levels and the Degree of Liver Damage in Fructose-Induced Metabolic Syndrome. Metabolic syndrome and related disorders 16, 350-357, doi:10.1089/met.2017.0162 (2018).

Eguchi, A., Wree, A. \& Feldstein, A. E. Biomarkers of liver cell death. Journal of hepatology 60, 1063-1074, doi:10.1016/j.jhep.2013.12.026 (2014).

Lee, J. et al. Accuracy of cytokeratin 18 (M30 and M65) in detecting non-alcoholic steatohepatitis and fibrosis: A systematic review and meta-analysis. PloS one 15, e0238717, doi:10.1371/journal.pone.0238717 (2020).

Wang, X. et al. Synergy analysis reveals association between insulin signaling and desmoplakin expression in palmitate treated HepG2 cells. PloS one 6, e28138, doi:10.1371/journal.pone.0028138 (2011).

Getsios, S., Huen, A. C. \& Green, K. J. Working out the strength and flexibility of desmosomes. Nature reviews. Molecular cell biology 5, 271-281, doi:10.1038/nrm1356 (2004).

Lee, S. J., Yoo, J. D., Choi, S. Y. \& Kwon, O. S. The expression and secretion of vimentin in the progression of non-alcoholic steatohepatitis. BMB reports 47, 457-462, doi:10.5483/bmbrep.2014.47.8.256 (2014).

Csak, T. et al. microRNA-122 regulates hypoxia-inducible factor-1 and vimentin in hepatocytes and correlates with fibrosis in diet-induced steatohepatitis. Liver international : official journal of the International Association for the Study of the Liver 35, 532-541, doi:10.1111/liv.12633 (2015).

Liu, J. et al. Long-chain fatty acid activates hepatocytes through CD36 mediated oxidative stress. Lipids in health and disease 17, 153, doi:10.1186/s12944-018-0790-9 (2018).

Schwabl, P. et al. The Non-Steroidal FXR Agonist Cilofexor Improves Portal Hypertension and Reduces Hepatic Fibrosis in a Rat NASH Model. Biomedicines 9, doi:10.3390/biomedicines9010060 (2021). 
Östlund, C., Chang, W., Gundersen, G. G. \& Worman, H. J. Pathogenic mutations in genes encoding nuclear envelope proteins and defective nucleocytoplasmic connections. Experimental biology and medicine (Maywood, N.J.) 244, 1333-1344, doi:10.1177/1535370219862243 (2019). Jacquemyn, J., Cascalho, A. \& Goodchild, R. E. The ins and outs of endoplasmic reticulumcontrolled lipid biosynthesis. EMBO reports 18, 1905-1921, doi:10.15252/embr.201643426 (2017). Östlund, C., Hernandez-Ono, A. \& Shin, J. Y. The Nuclear Envelope in Lipid Metabolism and Pathogenesis of NAFLD. Biology 9, doi:10.3390/biology9100338 (2020).

Dubik, N. \& Mai, S. Lamin A/C: Function in Normal and Tumor Cells. Cancers 12, doi:10.3390/cancers12123688 (2020).

Ajluni, N. et al. Spectrum of disease associated with partial lipodystrophy: lessons from a trial cohort. Clinical endocrinology 86, 698-707, doi:10.1111/cen.13311 (2017).

Zatloukal, K. Bringing the cell nucleus in the focus of NAFLD. Hepatology (Baltimore, Md.) 67, 1654-1656, doi:10.1002/hep.29696 (2018).

Desgrouas, C. et al. Unraveling LMNA Mutations in Metabolic Syndrome: Cellular Phenotype and Clinical Pitfalls. Cells 9, doi:10.3390/cells9020310 (2020).

Schwertheim, S. et al. Characterization of two types of intranuclear hepatocellular inclusions in NAFLD. Scientific reports 10, 16533, doi:10.1038/s41598-020-71646-y (2020).

Kwan, R. et al. Hepatocyte-Specific Deletion of Mouse Lamin A/C Leads to Male-Selective Steatohepatitis. Cellular and molecular gastroenterology and hepatology 4, 365-383, doi:10.1016/j.jcmgh.2017.06.005 (2017).

Hochmuth, L. et al. Sex-dependent dynamics of metabolism in primary mouse hepatocytes. Archives of toxicology 95, 3001-3013, doi:10.1007/s00204-021-03118-9 (2021).

Lefebvre, P. \& Staels, B. Hepatic sexual dimorphism - implications for non-alcoholic fatty liver disease. Nature reviews. Endocrinology, doi:10.1038/s41574-021-00538-6 (2021).

Balakrishnan, M. et al. Women Have a Lower Risk of Nonalcoholic Fatty Liver Disease but a Higher Risk of Progression vs Men: A Systematic Review and Meta-analysis. Clinical gastroenterology and hepatology : the official clinical practice journal of the American Gastroenterological Association 19, 61-71 e15, doi:10.1016/j.cgh.2020.04.067 (2021).

Shin, J. Y. et al. Nuclear envelope-localized torsinA-LAP1 complex regulates hepatic VLDL secretion and steatosis. The Journal of clinical investigation 129, 4885-4900, doi:10.1172/jci129769 (2019).

Stanchi, F. et al. TUBA8: A new tissue-specific isoform of alpha-tubulin that is highly conserved in human and mouse. Biochemical and biophysical research communications 270, 1111-1118, doi:10.1006/bbrc.2000.2571 (2000).

$\mathrm{Lu}, \mathrm{C}$. et al. Increased $\alpha$-tubulin1b expression indicates poor prognosis and resistance to chemotherapy in hepatocellular carcinoma. Digestive diseases and sciences 58, 2713-2720, doi:10.1007/s10620-013-2692-z (2013).

Rein-Fischboeck, L. et al. Tubulin alpha 8 is expressed in hepatic stellate cells and is induced in transformed hepatocytes. Molecular and cellular biochemistry 428, 161-170, doi:10.1007/s11010016-2926-4 (2017).

Malhi, H. \& Gores, G. J. Molecular mechanisms of lipotoxicity in nonalcoholic fatty liver disease. Seminars in liver disease 28, 360-369, doi:10.1055/s-0028-1091980 (2008).

Stewart, B. J., Doorn, J. A. \& Petersen, D. R. Residue-specific adduction of tubulin by 4hydroxynonenal and 4-oxononenal causes cross-linking and inhibits polymerization. Chemical research in toxicology 20,1111-1119, doi:10.1021/tx700106v (2007). 

of apolipoprotein B-100 inhibits secretion from HepG2 cells. Biochimica et biophysica acta 1791, 772-780, doi:10.1016/j.bbalip.2009.04.004 (2009).

Kabeya, Y. et al. LC3, a mammalian homologue of yeast Apg8p, is localized in autophagosome membranes after processing. The EMBO journal 19, 5720-5728, doi:10.1093/emboj/19.21.5720 (2000).

Hanna, R. A. et al. Microtubule-associated protein 1 light chain 3 (LC3) interacts with Bnip3 protein to selectively remove endoplasmic reticulum and mitochondria via autophagy. The Journal of biological chemistry 287, 19094-19104, doi:10.1074/jbc.M111.322933 (2012).

Park, H. S. et al. TXNIP/VDUP1 attenuates steatohepatitis via autophagy and fatty acid oxidation. Autophagy, 1-16, doi:10.1080/15548627.2020.1834711 (2020).

Naito, H. et al. High-fat and high-cholesterol diet decreases phosphorylated inositol-requiring kinase-1 and inhibits autophagy process in rat liver. Scientific reports 9, 12514, doi:10.1038/s41598-019-48973-w (2019).

Ramos, V. M., Kowaltowski, A. J. \& Kakimoto, P. A. Autophagy in Hepatic Steatosis: A Structured Review. Frontiers in cell and developmental biology 9, 657389, doi:10.3389/fcell.2021.657389 (2021).

Younan, N., Elattar, S., Farouk, M., Rashed, L. \& Estaphan, S. Dipeptidyl peptidase-4 inhibitors and aerobic exercise synergistically protect against liver injury in ovariectomized rats. Physiological reports 7, e14191, doi:10.14814/phy2.14191 (2019).

Robeva, R. et al. The interplay between metabolic dysregulations and non-alcoholic fatty liver disease in women after menopause. Maturitas 151, 22-30, doi:10.1016/j.maturitas.2021.06.012 (2021). for fibrotic non-alcoholic steatohepatitis. Liver international : official journal of the International Association for the Study of the Liver 39, 1315-1324, doi:10.1111/liv.14084 (2019).

Mohammed, M. A., Omar, N. M., Mohammed, S. A., Amin, A. M. \& Gad, D. F. FICK-3 Score Combining Fibrosis-4, Insulin Resistance and Cytokeratin-18 in Predicting Non-alcoholic Steatohepatitis in NAFLD Egyptian Patients. Pakistan journal of biological sciences : PJBS 22, 457466, doi:10.3923/pjbs.2019.457.466 (2019).

Dai, G. et al. The significance of IL-28B and CK-18 M30 levels in the diagnosis of non-alcoholic steatohepatitis in SD rats. Pathology, research and practice 216, 152901, doi:10.1016/j.prp.2020.152901 (2020).

Wong, V. W., Adams, L. A., de Lédinghen, V., Wong, G. L. \& Sookoian, S. Noninvasive biomarkers in NAFLD and NASH - current progress and future promise. Nature reviews. Gastroenterology \& hepatology 15, 461-478, doi:10.1038/s41575-018-0014-9 (2018).

Tada, T. et al. Predictive value of cytokeratin-18 fragment levels for diagnosing steatohepatitis in patients with nonalcoholic fatty liver disease. European journal of gastroenterology \& hepatology, doi:10.1097/meg.0000000000002176 (2021).

Altaf, B., Rehman, A., Jawed, S. \& Raouf, A. Association of liver biomarkers and cytokeratin-18 in Nonalcoholic fatty liver disease patients. Pakistan journal of medical sciences 36, 387-390, doi:10.12669/pjms.36.3.1674 (2020).

Mannery, Y. O., McClain, C. J. \& Vos, M. B. Keratin 18, Apoptosis, and Liver Disease in Children. Current pediatric reviews 7, 310-315, doi:10.2174/157339611796892364 (2011). 
Wu, G. et al. Complementary Role of Fibroblast Growth Factor 21 and Cytokeratin 18 in Monitoring the Different Stages of Nonalcoholic Fatty Liver Disease. Scientific reports 7, 5095, doi:10.1038/s41598-017-05257-5 (2017).

Safarian, M. et al. Effect of diet-induced weight loss on cytokeratin-18 levels in overweight and obese patients with liver fibrosis. Diabetes \& metabolic syndrome 13, 989-994, doi:10.1016/j.dsx.2019.01.005 (2019).

Takahashi, A. et al. Simple resistance exercise decreases cytokeratin 18 and fibroblast growth factor 21 levels in patients with nonalcoholic fatty liver disease: A retrospective clinical study. Medicine 99, e20399, doi:10.1097/md.0000000000020399 (2020).

Hempel, F. et al. Caspase-Cleaved Keratin 18 Measurements Identified Ongoing Liver Injury after Bariatric Surgery. Journal of clinical medicine 10, doi:10.3390/jcm10061233 (2021).

Vuppalanchi, R. et al. Relationship between changes in serum levels of keratin 18 and changes in liver histology in children and adults with nonalcoholic fatty liver disease. Clinical gastroenterology and hepatology: the official clinical practice journal of the American Gastroenterological Association 12, 2121-2130 e2121-2122, doi:10.1016/j.cgh.2014.05.010 (2014).

Xue, L. et al. Serum CK 18-M30 reflect liver pathological severity during NAFLD progression in a rat model. Pathology, research and practice 214, 1778-1786, doi:10.1016/j.prp.2018.08.016 (2018).

Kannt, A. et al. Activation of thyroid hormone receptor- $\beta$ improved disease activity and metabolism independent of body weight in a mouse model of non-alcoholic steatohepatitis and fibrosis. British journal of pharmacology 178, 2412-2423, doi:10.1111/bph.15427 (2021).

Perakakis, N., Stefanakis, K., Feigh, M., Veidal, S. S. \& Mantzoros, C. S. Elafibranor and liraglutide improve differentially liver health and metabolism in a mouse model of non-alcoholic steatohepatitis. Liver international : official journal of the International Association for the Study of the Liver 41, 1853-1866, doi:10.1111/liv.14888 (2021).

Fawzy, M. H., Saeed, N. M., El-Sherbiny, D. A. \& El-Demerdash, E. Eugenol modulates insulin sensitivity by upregulating insulin receptor substrate-2 in non-alcoholic fatty liver disease in rats. The Journal of pharmacy and pharmacology 73, 846-854, doi:10.1093/jpp/rgab032 (2021).

Gerges, S. H., Wahdan, S. A., Elsherbiny, D. A. \& El-Demerdash, E. Diosmin ameliorates inflammation, insulin resistance, and fibrosis in an experimental model of non-alcoholic steatohepatitis in rats. Toxicology and applied pharmacology 401, 115101, doi:10.1016/j.taap.2020.115101 (2020).

$\mathrm{He}$, Q. et al. Amlexanox reversed non-alcoholic fatty liver disease through IKKE inhibition of hepatic stellate cell. Life sciences 239, 117010, doi:10.1016/j.lfs.2019.117010 (2019).

Mollica, G. et al. L-carnitine supplementation attenuates NAFLD progression and cardiac dysfunction in a mouse model fed with methionine and choline-deficient diet. Digestive and liver disease : official journal of the Italian Society of Gastroenterology and the Italian Association for the Study of the Liver 52, 314-323, doi:10.1016/j.dld.2019.09.002 (2020).

Fishman, P. et al. The A3 adenosine receptor agonist, namodenoson, ameliorates non-alcoholic steatohepatitis in mice. International journal of molecular medicine 44, 2256-2264, doi:10.3892/jmm.2019.4364 (2019).

Lee, J. H. et al. Pharmaceutical Efficacy of Gypenoside LXXV on Non-Alcoholic Steatohepatitis (NASH). Biomolecules 10, doi:10.3390/biom10101426 (2020). 
Ahn, M. et al. Fermented black radish (Raphanus sativus L. var. niger) attenuates methionine and choline deficient diet-induced nonalcoholic fatty liver disease in mice. Food science \& nutrition 7 , 3327-3337, doi:10.1002/fsn3.1200 (2019).

Mohamed, R. H., Tarek, M., Hamam, G. G. \& Ezzat, S. F. Zoledronic acid prevents the hepatic changes associated with high fat diet in rats; the potential role of mevalonic acid pathway in nonalcoholic steatohepatitis. European journal of pharmacology 858, 172469, doi:10.1016/j.ejphar.2019.172469 (2019). Kundu, A. et al. EX-527 Prevents the Progression of High-Fat Diet-Induced Hepatic Steatosis and Fibrosis by Upregulating SIRT4 in Zucker Rats. Cells 9, doi:10.3390/cells9051101 (2020).

Li, S., Wang, C., Zhang, X. \& Su, W. Cytochrome P450 Omega-Hydroxylase 4a14 Attenuates Cholestatic Liver Fibrosis. Frontiers in physiology 12, 688259, doi:10.3389/fphys.2021.688259 (2021).

Tokinoya, K. et al. Effects of renalase deficiency on liver fibrosis markers in a nonalcoholic steatohepatitis mouse model. Molecular medicine reports 23, doi:10.3892/mmr.2021.11849 (2021). Wang, P. W. et al. Characterization of the Roles of Vimentin in Regulating the Proliferation and Migration of HSCs during Hepatic Fibrogenesis. Cells 8, doi:10.3390/cells8101184 (2019).

Nikam, A. et al. The PPARa Agonist Fenofibrate Prevents Formation of Protein Aggregates (Mallory-Denk bodies) in a Murine Model of Steatohepatitis-like Hepatotoxicity. Scientific reports 8 , 12964, doi:10.1038/s41598-018-31389-3 (2018).

Fang, Y. et al. Liraglutide Alleviates Hepatic Steatosis by Activating the TFEB-Regulated Autophagy-Lysosomal Pathway. Frontiers in cell and developmental biology 8, 602574, doi:10.3389/fcell.2020.602574 (2020).

$\mathrm{He}, \mathrm{Y}$. et al. The preventive effect of liraglutide on the lipotoxic liver injury via increasing autophagy. Annals of hepatology 19, 44-52, doi:10.1016/j.aohep.2019.06.023 (2020).

MacTaggart, B. \& Kashina, A. Posttranslational modifications of the cytoskeleton. Cytoskeleton (Hoboken, N.J.) 78, 142-173, doi:10.1002/cm.21679 (2021). 